\title{
Role of G Protein-Coupled Estrogen Receptor in Digestive System Carcinomas: A Minireview
}

This article was published in the following Dove Press journal:

OncoTargets and Therapy

\author{
Yu-an Qiu (1D) \\ Jianping Xiong ${ }^{2}$ \\ Tenghua $\mathrm{Yu}^{3}$ \\ 'Department of Critical Care Medicine, \\ Jiangxi Cancer Hospital, Nanchang \\ University Cancer Hospital, Nanchang, \\ 330029, People's Republic of China; \\ ${ }^{2}$ Department of Oncology, The First \\ Affiliated Hospital of Nanchang \\ University, Nanchang, 330006, People's \\ Republic of China; ${ }^{3}$ Department of Breast \\ Surgery, Jiangxi Cancer Hospital, \\ Nanchang University Cancer Hospital, \\ Nanchang, 330029, People's Republic of \\ China
}

\begin{abstract}
Digestive system carcinomas are one of the leading causes of cancer-related deaths worldwide. G protein-coupled estrogen receptor (GPER), a novel estrogen receptor, has been recognized as an important mediator in numerous cancer types. Recently, the function and clinical significance of GPER in digestive system carcinomas has been a subject of interest. Increasing evidence has revealed that GPER plays an important role as a potential biomarker in digestive system carcinomas. This work summarizes the recent literature and focuses on the emerging functional role of GPER in digestive system carcinomas, including gastric cancer, hepatocellular carcinoma, pancreatic cancer, and colorectal cancer. The potential application of GPER in novel strategies for the diagnosis and treatment of digestive system carcinomas is discussed and highlighted.
\end{abstract}

Keywords: GPER, digestive system carcinomas, prognostic indicator, therapeutic target

\section{Introduction}

Digestive system carcinomas have a high incidence and mortality in developing and developed countries and they constitute a heavy burden globally. ${ }^{1}$ Digestive tract cancers, such as gastric, esophageal, and liver cancers, are frequently diagnosed in China and are identified as the leading causes of cancer-related deaths. ${ }^{2}$ Early diagnosis and treatment could remarkably improve the prognosis of patients with digestive system carcinomas. However, due to the lack of useful biomarkers, patients with digestive system carcinomas are often diagnosed at an advanced stage, which is highly refractory to most systemic therapies. Therefore, to improve prognosis, novel effective biomarkers for early diagnosis in patients with such cancers must be identified.

GPER, formerly named as G protein-coupled receptor 30 (GPR30), is a member of $\mathrm{G}$ protein-coupled receptors (GPCRs), which belongs to the 7-transmembrane spanning $G$ protein-coupled receptor family and mediates the rapid cellular responses to estrogen, involving second messengers, kinases, and ion channels. ${ }^{3-7}$ GPER was identified and characterized from estrogen-induced activation of extracellular signal-regulated kinase (ERK) $1 / 2$ in classical nuclear estrogen receptor alpha/beta $\left(\mathrm{ER}_{\alpha / \beta}\right)$-negative breast cancer SKBR3 cells. ${ }^{8}$ The gene encoding GPER is located on the human chromosomal $7 \mathrm{p} 22.3$ region, and it consists of three exons. Only the third exon encodes a full-length 375 amino acid protein with seven membrane segments, and the relative molecular weight of the protein is approximately $42 \mathrm{kDa}$. The understanding of the function of GPER has made significant advances in the identification of GPER-selective agonists and antagonists and the
Correspondence: Tenghua Yu $\mathrm{Tel} / \mathrm{Fax}+86-79 \mid-88319832$

Email yutenghua0107@sina.cn
OncoTargets and Therapy 2021:14 26II-2622 
use of GPER knockout mice. ${ }^{9-11}$ Studies have shown that GPER can be localized in the plasma membrane at the cell surface $^{12}$ and intracellular membranes, such as the endoplasmic reticulum and Golgi apparatus. ${ }^{5}$ The nuclear localization of GPER has also been observed. ${ }^{13}$ GPER translocation has been shown to have a significant effect on resistance to chemotherapy in breast cancer. ${ }^{14}$

The contribution of GPER has been described in many physiological systems, such as the reproductive, nervous, endocrine, immune, and cardiovascular systems. ${ }^{15}$ Several studies have demonstrated that GPER mediates biological effects in various malignant tumors, including cancers of organs in which estrogen acts directly, such as breast, endometrial, and ovarian cancers, as well as other estrogenresponsive organ cancers, such as lung, prostate, and adrenocortical cancers. Yu et al ${ }^{16}$ reported that GPER enhanced cell viability and motility in triple-negative breast cancer cells. Li et $\mathrm{al}^{17}$ found that autocrine motility factor/GPER/ protein-serine-threonine kinase (AKT) signaling promotes endometrial cancer progression. Yan et $\mathrm{al}^{18}$ showed that GPER is involved in the proliferation, migration, and invasion of ovarian cancer cells. Conversely, GPER may act as a tumor suppressor in several cancer types, including lung cancer, ${ }^{19}$ prostate cancer, ${ }^{20}$ and adrenocortical carcinoma. ${ }^{21}$ Due to the different research conditions and the complex interactions between multiple estrogen receptors, contradictory results have been reported regarding the subcellular localization of GPER and its function, being described as both proliferative and pro-apoptotic in breast cancer. ${ }^{22}$ Similarly, numerous studies have suggested that GPER has dual roles (antitumorigenic or protumorigenic) in the pathogenesis, progression, and metastasis of malignant tumors. The causes of this phenomenon remain to be investigated.

To date, the molecular mechanisms and clinical significance of GPER in digestive system carcinomas remain obscure. This review summarized the present state of knowledge about the role of GPER in digestive system carcinomas (Table 1), of which GPER may emerge as a novel potential prognostic indicator and therapeutic target.

\section{GPER Ligands}

There are five main types of GPER ligands: steroids (Table 2), selective estrogen receptor downregulators (SERDs)/ selective estrogen receptor modulators (SERMs), phytoestrogens, synthetic estrogens, and synthetic compounds. Many studies have reported that the binding of estrogen (17 $\beta$-estradiol, E2) to
GPER exhibits high selectivity. ${ }^{4,15,23,24}$ In addition, other steroids, including estrone and $17 \alpha$-estradiol, exhibited very low affinities, whereas progesterone, cortisol, and testosterone did not bind to GPER. ${ }^{23}$ Furthermore, estriol has been reported to act as a GPER antagonist. ${ }^{25}$ Interestingly, among the therapeutic anti-estrogen agents, SERDs/SERMs, such as ICI 182780 (fulvestrant), tamoxifen, and raloxifene, were also shown to act as agonists of GPER as opposed to their antagonistic action towards $\mathrm{ER}_{\alpha / \beta} \cdot{ }^{8,23,26,27}$ Many synthetic estrogenic compounds, including pesticides, herbicides, and plasticizers (eg bisphenols, methoxychlor, alkylphenols, polychlorinated biphenyls, dioxins, and phthalates) have been demonstrated to activate GPER. ${ }^{28,29}$ Some phytoestrogens, such as quercetin, genistein, daidzein, resveratrol, oleuropein, and hydroxytyrosol, also bind to GPER.$^{30-33}$ Studies clarifying the potential physiological and pathophysiological functions of GPER are substantially facilitated by extremely high GPER-selective compounds sharing the scaffold domain of a tetrahydro-3H-cyclopenta-[c]quinoline, such as G1, G15, and G36, which serve as useful probes to stimulate (G1) or antagonize (G15 and G36) GPER signaling. ${ }^{9,10,34}$ Recently, based on a computational screen, a new compound, 2-cyclohexyl-4-isopropyl-N-(4-methoxybenzyl) aniline (CIMBA) was designed and synthesized, which exhibits high selectivity and superior antagonism for GPER and reduces the formation of estrogen-induced cholesterol gallstones in female mice. ${ }^{35}$

GPER ligands may serve as novel pharmacological agents for treating human diseases. ${ }^{36}$ Recent preclinical studies have shown that chronic administration of G1 could restore fat, glucose, and lipid homeostasis in mouse models. ${ }^{37}$ This observation indicates that chronic GPER signaling has potential implications for the role of GPER in cancer, as metabolic syndrome is an independent risk factor for cancer. ${ }^{38} \mathrm{G} 1$ is currently undergoing Phase I clinical trials for its antitumor properties. ${ }^{39}$

Models explaining estrogen-induced carcinogenesis in breast and gynecological cancers have focused on the ERdependent mechanisms of cellular proliferation and somatic mutations. ${ }^{40}$ However, a protective effect of estrogen has been suggested to explain the male predominance in cancers of the digestive tract, such as esophageal, gastric, and liver cancers. $^{41,42}$ Soy and soy-based foods have been used as basic traditional ingredients in the diets of the Asian population for thousands of years. Soy isoflavones such as daidzein and genistein are polyphenols with estrogenic properties. ${ }^{43}$ Soy intake has received wide attention because of its potential role in reducing the risk of gastrointestinal cancer. $^{44-46}$ Bisphenol A (BPA) and phthalates, classified as 
Table I Summary of the Role of GPER in Various Digestive System Malignancies

\begin{tabular}{|c|c|c|c|c|c|c|}
\hline Types & $\begin{array}{l}\text { GPER } \\
\text { Expression* }\end{array}$ & Function & Ligand & Signaling Pathways & Study Objects & Reference \\
\hline \multirow[t]{3}{*}{ GC } & $\begin{array}{l}\text { Down- } \\
\text { regulated }\end{array}$ & Predict good prognosis & $\begin{array}{l}\text { Non- } \\
\text { specified }\end{array}$ & EMT & $\begin{array}{l}\text { Bioinformatics } \\
\text { Clinical samples } \\
\text { In vitro }\end{array}$ & [76] \\
\hline & $\begin{array}{l}\text { Down- } \\
\text { regulated }\end{array}$ & Increase cell death & GI & ER stress & $\begin{array}{l}\text { Clinical } \\
\text { In vitro } \\
\text { In vivo }\end{array}$ & [77] \\
\hline & Up-regulated & Predict poor prognosis & $\begin{array}{l}\text { Non- } \\
\text { specified }\end{array}$ & Non-specified & Bioinformatics & [78] \\
\hline \multirow[t]{8}{*}{$\mathrm{HCC}$} & $\begin{array}{l}\text { Non- } \\
\text { specified }\end{array}$ & Regulate iron metabolism & $\begin{array}{l}\mathrm{E} 2 ; \mathrm{GI} \\
\mathrm{ICI} \\
\mathrm{I} 82720\end{array}$ & GPR30/BMP6 & $\begin{array}{l}\text { In vitro } \\
\text { In vivo }\end{array}$ & [85] \\
\hline & $\begin{array}{l}\text { Non- } \\
\text { specified }\end{array}$ & Antiviral & $\begin{array}{l}\text { E2; GI; } \\
\text { GI5 } \\
\text { tamoxifen }\end{array}$ & GPR30/MMP9 & In vitro & [86] \\
\hline & $\begin{array}{l}\text { Non- } \\
\text { specified }\end{array}$ & Mechanical reprogramming & Tamoxifen & GPER/RhoA/myosin & In vitro & [87] \\
\hline & $\begin{array}{l}\text { Non- } \\
\text { specified }\end{array}$ & $\begin{array}{l}\text { Inhibit proliferation; Stimulate } \\
\text { apoptosis }\end{array}$ & E2; GI & GPER/ERK & In vitro & [88] \\
\hline & $\begin{array}{l}\text { Down- } \\
\text { regulated }\end{array}$ & Regulate inflammatory responses & GI & Non-specified & $\begin{array}{l}\text { Clinical samples } \\
\text { In vitro } \\
\text { In vivo }\end{array}$ & [69] \\
\hline & Up-regulated & Promote tumor development & E2 & GPER/PI3K/AKT/mTOR & $\begin{array}{l}\text { Clinical samples } \\
\text { In vivo }\end{array}$ & [89] \\
\hline & $\begin{array}{l}\text { Non- } \\
\text { specified }\end{array}$ & Increase miR-2I transcription & $\begin{array}{l}\text { DHEA; } \\
\text { GI; GI5 } \\
\text { ICI } \\
\text { I82720 }\end{array}$ & GPER/ERK & In vitro & [90] \\
\hline & $\begin{array}{l}\text { Non- } \\
\text { specified }\end{array}$ & $\begin{array}{l}\text { Up-regulate FASN; } \\
\text { Increase cell growth }\end{array}$ & $\mathrm{E} 2 ; \mathrm{GI}$ & GPER/ERK/c-fos/AP-I & In vitro & [92] \\
\hline \multirow[t]{5}{*}{ PDAC } & $\begin{array}{l}\text { Non- } \\
\text { specified }\end{array}$ & Sensitize cells to chemotherapy & $\begin{array}{l}\text { AXPI07- } \\
\text { II } \\
\text { GI; GI5 }\end{array}$ & GPER/MAPK & $\begin{array}{l}\text { Bioinformatics } \\
\text { In vitro } \\
\text { In vivo }\end{array}$ & [96] \\
\hline & $\begin{array}{l}\text { Non- } \\
\text { specified }\end{array}$ & $\begin{array}{l}\text { Inhibit mechanotransduction and } \\
\text { invasion }\end{array}$ & $\begin{array}{l}\text { GI } \\
\text { GI5 }\end{array}$ & GPER/PKA/RhoA/myosin2 & $\begin{array}{l}\text { Bioinformatics } \\
\text { In vitro }\end{array}$ & [97] \\
\hline & $\begin{array}{l}\text { Non- } \\
\text { specified }\end{array}$ & $\begin{array}{l}\text { Induce tumor regression; } \\
\text { Increase cell immunogenicity }\end{array}$ & GI & Non-specified & $\begin{array}{l}\text { Clinical samples } \\
\text { In vitro } \\
\text { In vivo }\end{array}$ & [72] \\
\hline & $\begin{array}{l}\text { Non- } \\
\text { specified }\end{array}$ & $\begin{array}{l}\text { Reprogram the tumor } \\
\text { Microenvironment; } \\
\text { Increase apoptosis }\end{array}$ & Tamoxifen & GPER/HIF-I $\alpha$ & $\begin{array}{l}\text { In vitro } \\
\text { In vivo }\end{array}$ & [99] \\
\hline & $\begin{array}{l}\text { Non- } \\
\text { specified }\end{array}$ & $\begin{array}{l}\text { Mechanically regulate the tumor } \\
\text { microenvironment }\end{array}$ & Tamoxifen & GPER/RhoA & $\begin{array}{l}\text { In vitro } \\
\text { In vivo }\end{array}$ & {$[100]$} \\
\hline
\end{tabular}


Table I (Continued).

\begin{tabular}{|c|c|c|c|c|c|c|}
\hline Types & $\begin{array}{l}\text { GPER } \\
\text { Expression* }\end{array}$ & Function & Ligand & Signaling Pathways & Study Objects & Reference \\
\hline \multirow[t]{5}{*}{ CRC } & $\begin{array}{l}\text { Down- } \\
\text { regulated }\end{array}$ & $\begin{array}{l}\text { Inhibit proliferation; } \\
\text { Induce cell cycle arrest; Increase the } \\
\text { mitochondrial related apoptosis }\end{array}$ & GI & $\begin{array}{l}\text { GPER/ROS/ERKI/2 GPER/ } \\
\text { KK } \alpha / / \kappa B \alpha / N F-\kappa B \text { GPER/GSK- } \\
3 \beta / N F-\kappa B\end{array}$ & $\begin{array}{l}\text { Bioinformatics } \\
\text { Clinical samples } \\
\text { In vitro } \\
\text { In vivo }\end{array}$ & {$[102]$} \\
\hline & $\begin{array}{l}\text { Up-regulated } \\
\text { (hypoxia) }\end{array}$ & $\begin{array}{l}\text { Induce cell migration and proliferation } \\
\text { (hypoxia); } \\
\text { Suppress cell migration and } \\
\text { proliferation (normoxia) }\end{array}$ & E2 & $\begin{array}{l}\text { GPER/HIF-I } \alpha \\
\text { GPER/VEGFA }\end{array}$ & $\begin{array}{l}\text { Bioinformatics } \\
\text { In vitro }\end{array}$ & {$[105]$} \\
\hline & $\begin{array}{l}\text { Non- } \\
\text { specified }\end{array}$ & Hydrolyze $E_{1} S$ & $\begin{array}{l}\text { E2; GI } \\
\text { tamoxifen } \\
\mathrm{ICI} \\
\mathrm{I} 82780\end{array}$ & GPER/STS & In vitro & {$[106]$} \\
\hline & Up-regulated & $\begin{array}{l}\text { Augment proliferation; } \\
\text { Predict poor outcomes }\end{array}$ & $\begin{array}{l}\text { E2; GI; } \\
\text { GI5 }\end{array}$ & Non-specified & $\begin{array}{l}\text { Bioinformatics } \\
\text { In vitro } \\
\text { In vivo }\end{array}$ & {$[107]$} \\
\hline & $\begin{array}{l}\text { Non- } \\
\text { specified }\end{array}$ & $\begin{array}{l}\text { Up-regulate FASN; } \\
\text { Increase cell growth }\end{array}$ & $\mathrm{E} 2 ; \mathrm{GI}$ & GPER/ERK/c-fos/AP-I & In vitro & [92] \\
\hline
\end{tabular}

Note: *GPER expression levels in tumor tissues or cells compared to those in normal tissues and cells.

Abbreviations: AXPI07-II, a genistein analogue; CRC, colorectal cancer; DHEA, dehydroepiandrosterone; GC, gastric cancer; HCC, hepatocellular carcinoma; IKB, inhibitor of nuclear factor-KB; IKK, IkappaB kinase; MAPK, mitogen-activated protein kinases; mTOR, mammalian target of rapamycin; PDAC, pancreatic ductal adenocarcinoma; PKA, protein kinase A; ROS, reactive oxygen species; VEGFA, vascular endothelial growth factor $\mathrm{A}$.

synthetic plasticizers, can exert endocrine disruption due to their weak estrogenic properties and increased risk of cancer. ${ }^{47,48} \mathrm{BPA}$ exposure not only increases the risk of colon cancer, but also induces chemotherapy resistance, ${ }^{49}$ which reflects its potential importance in digestive carcinomas. As such, a better understanding of the role of GPER in digestive system carcinomas may help to elucidate the potential mechanisms to improve prevention and management of the disease.

\section{GPER-Activated Signaling Pathways}

As a classical GPCR, GPER exhibits the hallmarks of a plasma membrane receptor that manifests its actions through $G$ protein-dependent cell signaling. ${ }^{50}$ GPER activation induces heterotrimeric $G$ proteins, which then activate multiple downstream effectors, including adenylyl cyclase, resulting in cyclic adenosine monophosphate (cAMP)/protein kinase A/cAMP response element binding protein production, an increase in

Table 2 Summary of the Type of GPER Ligands

\begin{tabular}{|l|l|l|l|l|}
\hline Steroid Hormones & SERDs/SERMs & Synthetic Estrogens & Phytoestrogens & Synthetic Compounds \\
\hline I7ß-estradiol & ICII82780 & Bisphenols & Quercetin & GI \\
\hline $17 \alpha$-estradiol & Tamoxifen & Methoxychlor & Genistein & GI5 \\
\hline Estrone & Raloxifene & Alkylphenols & Daidzein & G36 \\
\hline Estriol & & Polychlorinated biphenyls & Resveratrol & CIMBA \\
\hline & & Dioxins & Oleuropein & \\
\hline & & Phthalates & Hydroxytyrosol & \\
\hline
\end{tabular}


Src-like nonreceptor tyrosine kinases (Src) and sphingosine kinase (SphK). The latter two signals induce the activation of matrix metalloproteinases (MMPs), which cleave pro-heparin-binding EGF-like growth factor (HB-EGF), liberating free HB-EGF, which in turn could transactivate epidermal growth factor receptors (EGFRs). EGFR activation appears to be involved in the activation of mitogen-activated protein kinases (MAPKs)/ERK pathway. ${ }^{51-54}$ EGFR activation also triggers phosphatidylinositol 3-kinases (PI3Ks)/AKT. ${ }^{55}$ The additional downstream pathways reported to be activated by GPER include protein kinase $\mathrm{C}$, calcium mobilization, and Hippo/Yes-associated protein signaling. ${ }^{56-58}$ The GPER-mediated signaling pathways are outlined in Figure 1.

\section{GPER in Metabolic Syndrome, Clinical Targeted-Therapy, and the Immune System}

Estrogen is an important modulator of metabolic disorders in both humans and animal models; ${ }^{59}$ thus, it is expected that GPER plays a vital role in metabolic regulation. Similar to the pathological features of a patient with metabolic syndrome, GPER knockout mice show a phenotype marked by vascular disease, ${ }^{60}$ impaired glucose tolerance, ${ }^{61,62}$ dyslipidemia, ${ }^{62}$ and obesity. ${ }^{60}$ A large sample $(38,940$ cancer cases) meta-analysis showed that the presence of metabolic syndrome was associated with colorectal, liver, and stomach cancer in men and pancreatic cancer in women. ${ }^{63}$ From the perspective of GPER-mediated energy metabolic coupling

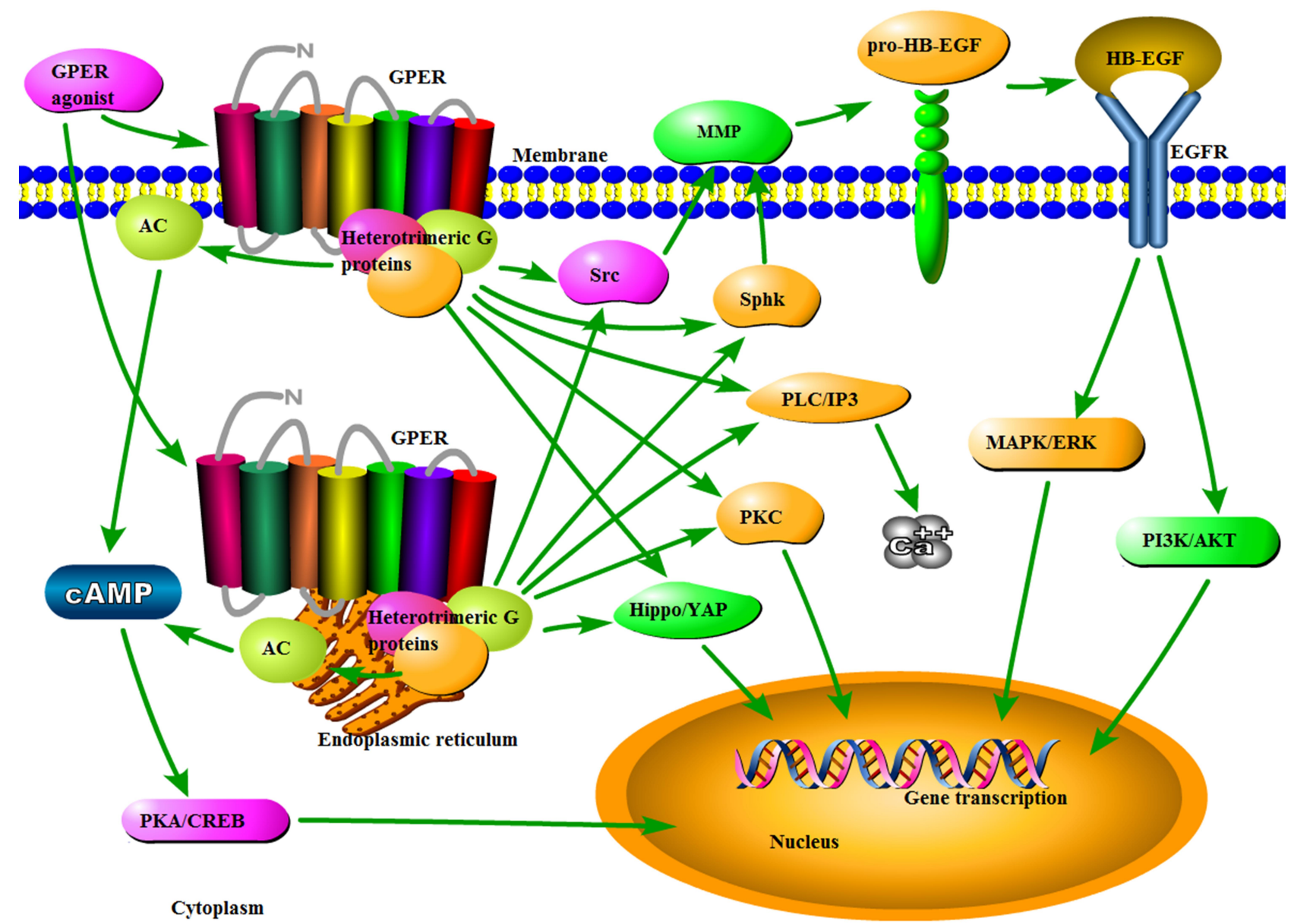

Figure I Schematic diagram of the GPER signaling pathways. Once the binding of the agonist is generated, GPER can induce heterotrimeric G proteins, resulting in multiple downstream events, including AC/CAMP/PKA/CREB, Src, and SphK. MMP, activated by the latter two signals, may cleave pro-HB-EGF and liberate free HB-EGF, which in turn transactivates EGFR. Subsequently, EGFR activation appears to be involved in the activation of MAPK/ERK and PI3K/AKT pathways. Additionally, the additional signals activated by GPER include PLC/IP3/calcium mobilization, PKC, and Hippo/YAP signaling.

Abbreviations: AC, adenylyl cyclase; CREB, cAMP response element binding protein; IP3, inositol triphosphate; MAPK, mitogen-activated protein kinases; PKA, protein kinase A; PKC, protein kinase C; PLC, phospholipase C; YAP, Yes-associated protein. 
(EMC) in clinical targeted therapy, cytoplasmic GPER translocation in cancer-associated fibroblasts mediates the cAMP/ PKA/CREB/glycolytic axis and confers breast tumor cells with Her-2-targeted therapy (herceptin) resistance. ${ }^{14}$ Moreover, inhibition of EGFR by gefitinib reduces the expression of GPER and subsequently prevents E2-induced cell growth in triple-negative breast cancer cells. ${ }^{64}$

In the immune system, GPER is expressed in each population of immune cells, including peripheral $B$ and T lymphocytes, monocytes, eosinophils, and neutrophils. ${ }^{65}$ In addition, it regulates estrogenic effects on immune functions in humans and other species. ${ }^{66,67}$ The immunomodulatory effect of GPER has also been beneficial in immune-mediated diseases such as multiple sclerosis, liver fibrosis, and autoimmune encephalomyelitis by reducing the levels of inflammatory cytokines and upregulating programmed death-1 (PD-1) on $\mathrm{CD} 4^{+}$Foxp $3^{+}$regulatory T cells. ${ }^{68-70}$ Systematically administered G1 was well tolerated in mice and markedly increased the efficacy of immune checkpoint blockade in melanoma and pancreatic cancer. $^{71,72}$

\section{GPER in Gastric Cancer (GC)}

$\mathrm{GC}$ is the fourth most commonly diagnosed cancer among men and the fifth among women worldwide, with an estimated 951,600 new cases and 723,100 deaths in $2012 .^{73}$ In China, GC is the second leading cause of cancer-related deaths, with an estimated 498,000 deaths in $2015 .^{2}$ The GC rates are approximately twice as high in men as in women, ${ }^{73}$ possibly due to the presence of estrogen in women. Gastrectomy and chemotherapy are currently the main therapeutic options for patients with $\mathrm{GC} .^{74}$ The rate of early diagnosis of GC is dismal because it is symptom-free. $^{75}$ Most patients present with advanced stage (locally advanced or metastatic) GC and have a poor prognosis. Therefore, identifying novel diagnostic and prognostic biomarkers and investigating specific therapeutic targets for GC are urgently needed.

Tian et $\mathrm{al}^{76}$ demonstrated that GPER mRNA and protein levels were downregulated in GC tissues and cells, and the decreased expression of GPER protein was an independent risk factor for poor prognosis in patients with GC. Furthermore, bioinformatics data showed that GPER DNA promoter methylation may be involved in the reduced expression of GPER in GC and that GPER may act as a tumor suppressor through the regulation of the epithelial-mesenchymal transition (EMT) pathway. ${ }^{76}$ Another study similarly indicated that GPER mRNA levels were significantly lower in GC tissues than in normal tissues, and a stage-dependent decrease was found in the GPER expression of GC on the basis of GPER fluorescence intensity in cancer stages I and II (45\% and 30\%) versus stages III and IV (25\% and 20\%, respectively). ${ }^{77}$ The induction of pERK-dependent endoplasmic reticulum stress via GPER signaling may increase G1's chemotherapeutic effect in the GC cells. ${ }^{77}$ However, by contrast, a bioinformatics screening for hub genes associated with GC by Zheng et al indicated that GPER was highly expressed in GC tissues and that the overexpression of GPER was associated with poor survival. ${ }^{78}$

In conclusion, GPER is associated with GC prognosis. As a GPER agonist, G1 induced gastric cancer cell apoptosis. However, a study by Zheng et al provided inconsistent evidence. ${ }^{78}$ The possible reason is that this study only carried out clip data and a bioinformatics analysis and lacked clinical data and in vitro or in vivo experimental validation. Furthermore, the database and research tools used in this study were different from those used in a previous study. To our knowledge, few studies have focused on the role of GPER in GC. More investigations are required to determine whether GPER can be a potential prognostic biomarker and therapeutic target for GC in the future.

\section{GPER in Hepatocellular Carcinoma (HCC)}

Primary liver cancer (PLC) is an aggressive malignancy with a generally poor prognosis, with an estimated 782,500 new cases and 745,500 deaths worldwide in $2012 .^{73}$ In China, PLC is the third leading cause of cancerrelated deaths, with an estimated 422,100 deaths in $2015 .^{2}$ HCC, which represents approximately $90 \%$ of PLC, is generally caused by hepatitis B virus (HBV) and hepatitis $\mathrm{C}$ virus (HCV) infection and alcohol use. ${ }^{79,80}$ The HCC rates in men are usually 2-4 times higher than those in women, thus suggesting the vital role of sex hormones in HCC pathogenesis. ${ }^{81,82}$ A clinical study suggested a protective role of estrogen in $\mathrm{HCC}$, as higher $\mathrm{HCC}$ morbidity and mortality were found in male patients. ${ }^{83}$ However, the mechanisms involved in estrogen-mediated protection in HCC remain to be explored.

The role of GPER in HCC has been investigated in recent years. Hepcidin, a liver-derived iron regulatory protein, regulates iron absorption in the small intestine via internalization and degradation of ferroportin, an 
exporter of iron.$^{84}$ E2 and ICI 182,720 increased hepcidin expression in HepG2 cells through a GPER/bone morphologic protein 6 (BMP6)-dependent mechanism, indicating that estrogen decreases iron absorption in the intestine. ${ }^{85}$ This finding provides a new perspective for explaining the gender differences in iron storage in the body. Ulitzky et $\mathrm{al}^{86}$ reported that GPER activation downregulated HCV entry and spread by promoting occludin cleavage through MMP-9, thus providing a new insight into a novel antiviral effect. Cortes et $\mathrm{al}^{87}$ showed that tamoxifen mechanically deactivated hepatic stellate cells (HSCs), whose activation triggers and perpetuates liver fibrosis in HCC via the GPER/GTPase Ras homolog family member A (RhoA)/myosin axis. These results suggest that GPER-mediated estrogen signaling is an option for the mechanical reprogramming of HSCs in the tumor microenvironment. Shen et $\mathrm{al}^{88}$ revealed that E2 and G1 antagonized the oncogenic actions of leptin in HepG2 cells by inhibiting cell proliferation and stimulating cell apoptosis, which was partly associated with increased ERK activation mediated by GPER. Wei et $\mathrm{al}^{69}$ showed that GPER mRNA and protein levels were significantly lower in HCC tissues than in matched non-tumor tissues. Interestingly, modulating GPER expression did not affect the viability and proliferation of HCC cells in vitro. ${ }^{69}$ Furthermore, GPER knockout in a diethylnitrosamineinduced mouse tumor model significantly facilitated liver tumorigenesis by promoting inflammation and fibrosis, thus revealing that GPER may inhibit HCC tumorigenesis by modulating inflammatory responses. ${ }^{69}$ However, Chaturantabut et $\mathrm{al}^{89}$ indicated that the activation of GPER promoted liver growth and tumor development via the PI3K/mammalian target of rapamycin signaling in zebrafish. They also found that human HCC samples had increased GPER expression levels compared to non-tumor tissues. Teng et $\mathrm{al}^{90}$ suggested that a rapid increase in microRNA-21, an oncomiR in HCC, transcription stimulated by dehydroepiandrosterone in HepG2 cells involved GPER activation, which increased ERK1/2 and c-Src phosphorylation. Activation of lipid metabolism is present in many tumors. Fatty acid synthase (FASN) is necessary for cancer cell survival, growth, and migration. ${ }^{91} \mathrm{E} 2$ and G1 upregulated FASN expression in HepG2 cells via GPER activation, which involved GPER/ERK/c-fos/activator protein 1 (AP-1) signaling. ${ }^{92}$

In summary, GPER may play a crucial role in HCC, suggesting its potential as a therapeutic target. However, the results of current studies illustrate the complexity of the role of GPER in HCC, including metabolism, antivirus, microenvironment, immunity, tumor growth, and epigenetic regulation. Genetic variability has been discussed as a cause of HCC development. ${ }^{93}$ Not surprisingly, GPER may have bilateral effects on HCC proliferation in different species. In populations with different genetic backgrounds, diets, or possibly environmental factors, the GPER expression in HCC tissues in different studies may vary significantly. Whether GPER contributes to gender differences in HCC requires further exploration, especially in large sample clinical studies that include complete prognostic data.

\section{GPER in Pancreatic Cancer (PDAC)}

PDAC is one of the deadliest cancers and is poorly responsive to current treatments. PDAC is projected to become the second leading cause of cancer-related deaths in the United States by $2030 .{ }^{94}$ In 2015, an estimated 90,100 new cases of PDAC and 79,400 deaths were reported in China. ${ }^{2}$ Thus, finding new therapeutic targets to inhibit PDCA is urgently needed.

Andersson et $\mathrm{al}^{95}$ suggested that the use of hormone replacement therapy (HRT), in particular an estrogenonly regimen, was associated with a decreased risk of PDAC in women. A group revealed that high GPER expression in PDAC was indicative of improved survival, and a genistein analog sensitized PDAC patient-derived xenografts to chemotherapy through GPER activation. ${ }^{96}$ Rice et $\mathrm{al}^{97}$ also found that high GPER expression was associated with improved survival and lengthened relapse-free time in PDAC. Furthermore, GPER activation represses cell proliferation, mechanotransduction, cell contractility, EMT, and basement membrane invasion in cancer cells via RhoA.$^{97}$ Natale et al ${ }^{72}$ suggested that GPER activation in G1 decreased PDAC cell proliferation and increased tumor cell immunogenicity. In addition, G1 was well tolerated in mice, promoted tumor regression, enhanced the efficacy of programmed cell death protein-1 targeted immune therapy, and prolonged survival. ${ }^{72}$

PDAC is associated with severe tissue fibrosis or desmoplasia, which provides a distinct microenvironment that regulates pancreatic tumor behavior, including its ability to progress and metastasize, as well as its resistance to drugs. ${ }^{98}$ Therefore, tumor stroma is not a bystander in PDAC evolution, and targeting the stromal tissue may open up a promising option for PDAC therapy. Cortes et $\mathrm{al}^{99}$ demonstrated that tamoxifen 
regulated peri-tumoral stromal remodeling and the fibrovascular tumor microenvironment in PDAC tissues via the GPER/hypoxia-inducible factor-1 alpha (HIF-1 $\alpha$ ) axis. Another study by Cortes et al indicated that tamoxifen suppressed myofibroblastic differentiation of pancreatic stellate cells via GPER/RhoA signaling and lowered collagen deposition and macrophage infiltration in the tumor microenvironment. ${ }^{100}$ These findings highlight the potential of GPER as an effective mechanoregulator of the tumor microenvironment in PDAC.

In summary, the current evidence suggests that GPER may be an important cancer suppressor in PDAC. G1 and tamoxifen may provide novel avenues for PDAC therapeutics. Clinical trials are needed to verify the clinical utility of GPER as a useful prognostic indicator and therapeutic target for PDAC.

\section{GPER in Colorectal Cancer (CRC)}

Colorectal cancer (CRC) is one of the most common cancer types worldwide. ${ }^{1}$ In China, an estimated 376,300 (215,700 males; 160,600 females) new cases of CRC and 191,000 (111,100 males; 80,000 females) deaths were reported in $2015 .^{2}$ Although the incidence and mortality of women are lower than those of men, the role of estrogen in colorectal cancer remains controversial. ${ }^{101}$ Despite advances in multimodal therapies, the survival of patients with advanced CRC remains poor. Identifying reliable biomarkers is beneficial for improving the prognosis of CRC.

GPER expression in CRC tissues was significantly lower than that in matched adjacent normal tissues, and patients whose tumors expressed less GPER had a poor prognosis. ${ }^{102}$ In addition, GPER expression in CRC cells and clinical tissues is downregulated by DNA promoter methylation and histone $\mathrm{H} 3$ acetylation. ${ }^{102}$ The activation of GPER by G1 inhibits proliferation, induces cell cycle arrest, increases mitochondrial-related apoptosis, and elevates endoplasmic reticulum stress in CRC cells via multiple intracellular signaling pathways, including reactive oxygen species/ERK1/2, IkappaB kinase/inhibitor of nuclear factor- $\kappa \mathrm{B}(\mathrm{NF}-\kappa \mathrm{B})$, and glycogen synthase

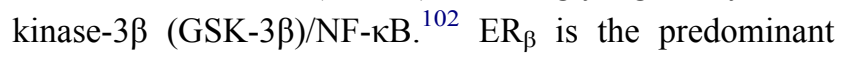
estrogen receptor in normal colonic epithelium, and the decline in $\mathrm{ER}_{\beta}$ expression paralleled the dedifferentiation of malignant colon cells. ${ }^{103,104}$ Estrogen may have a protective effect depending on the expression of $\mathrm{ER}_{\beta}{ }^{103}$ Although $\mathrm{ER}_{\beta}$ is frequently lost in the hypoxic microenvironment as CRC malignancy progresses, hypoxia induces the expression of GPER in CRC cells. ${ }^{105}$ Bustos et al ${ }^{105}$ found that E2 treatment, through the action of GPER, suppressed CRC cell migration and proliferation in normoxia but enhanced them in hypoxia. This finding was consistent with the repression or enhancement of HIF-1 $\alpha$ and vascular endothelial growth factor A expression under normoxic and hypoxic conditions, respectively. It appears that the interpretation of the role of E2 in CRC progression is complicated by the relative expression levels of estrogen receptor isoforms and the action of GPER under varying ambient oxygen tension. A cohort study showed that GPER expression was associated with poor relapse-free survival in female patients with stage 3 and $4 \mathrm{CRC}$, but not in male patients with matched stages. ${ }^{105}$ Local estrogen may stimulate the development of CRC. ${ }^{70}$ GPER stimulation, through E2 and G1, increased CRC steroid sulfatase (STS) activity, which could hydrolyze estrone sulfate $\left(E_{1} S\right)$ and promote CRC cell proliferation, suggesting that HRT (primarily consisting of $\mathrm{E}_{1} \mathrm{~S}$ ) may lead to undesired effects in patients with CRC. ${ }^{106,107}$ Tamoxifen and ICI 182780 also enhanced STS activity via GPER activation, indicating that these agents could play negative roles in CRC development and progression. ${ }^{106}$ Additionally, GPER activation further upregulated FASN expression in colorectal LoVo cancer cells via ERK/c-fos/AP-1 signaling. ${ }^{92}$

The precise role of GPER in CRC is currently illdefined, which may result from variations in cell and animal models under different experimental conditions and protocols. On the other hand, the complex cross-talk between GPER and the genomic actions of estrogen may lead to ambiguous results. In addition, the role of GPER in CRC may change depending in part on the aerobic/anoxic conditions of the local tumor microenvironment. Even so, GPER is a significant mediator of CRC progression. Further studies are required to explore the factors influencing GPER exerting function in CRC.

\section{Conclusion}

Clinical and experimental data have shown that GPER signaling plays an important role in digestive system carcinomas. Taken together, GPER is involved in many cellular processes, including proliferation, apoptosis, migration, invasion, vascularization, inflammation, immunogenicity, microenvironment, cell cycle regulation, endoplasmic reticulum stress, EMT, estrogen metabolism, and fatty acid regulation in digestive system carcinomas. However, while being a well-established tumour suppressor in 
pancreatic cancer, the role of GPER in other digestive system carcinomas is currently controversial. The possible reasons include the following: First, the role of GPER varies considerably at different stages of tumor development. Second, the biological effect of GPER is closely related to oxygen levels in cancer cells. Third, GPER may show diverse mechanisms in different research objects and conditions. Fourth, the complexity of the physiological effects of estrogen and potential cross-talk among various steroid receptors may affect the accurate interpretation of GPER. Differentiating the molecular and phenotypic subgroups of individuals may be essential to pinpoint the contributions of GPER in digestive system carcinomas. Further studies are needed to elucidate the relative molecular mechanisms and regulatory networks of GPER in digestive system carcinomas to develop prevention, diagnostic, and therapeutic strategies. Finally, the information related to the role of GPER in pancreatic cancer indicated that GPER may serve as an effective predictor and therapeutic target for this highly malignant disease.

\section{Abbreviations}

AKT, protein-serine-threonine kinase; AP-1, activator protein 1; BMP6, bone morphologic protein-6; cAMP, cyclic Adenosine monophosphate; CRC, colorectal cancer; EGFRs, epidermal growth factor receptors; EMC, energy metabolic coupling; EMT, epithelial-mesenchymal transition; ERK, extracellular signal-regulated kinase; ER, endoplasmic reticulum; $\mathrm{ER}_{\alpha}$, estrogen receptor alpha; $\mathrm{ER}_{\beta}$, estrogen receptor beta; $E_{1} S$, estrone sulfate; FASN, fatty acid synthase; GC, gastric cancer; GPCRs, G protein-coupled receptors; GPER, G protein-coupled estrogen receptor; GPR30, G proteincoupled receptor 30; GSK-3 $\beta$, Glycogen Synthase Kinase$3 \beta$; GTP, guanosine triphosphate; HB-EGF, heparin-binding EGF-like growth factor; HCV, hepatitis $\mathrm{C}$ virus; HIF-1 $\alpha$, hypoxia-inducible factor-1 alpha; HCC, hepatocellular carcinoma; HSCs, hepatic stellate cells; MMPs, matrix metallo-

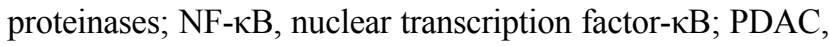
pancreatic ductal adenocarcinoma; PERK, proteinkinaseRlike ER kinase; PI3K, phosphatidylinositol 3-kinases; PLC, primary liver cancer; RhoA, GTPase Ras homolog family member A; SphK, sphingosine kinase; Src, Src-like nonreceptor tyrosine kinases; STS, steroid sulfatase.

\section{Data Sharing Statement}

The authors confirm that the data used to support the findings of this study are available from the corresponding author upon request.

\section{Funding}

This work was supported by the Youths Program of National Natural Science Foundation of China (81702641), the Excellent Youths Program of Natural Science Foundation of Jiangxi Province (2018ACB21042), the Youths Program of Natural Science Foundation of Jiangxi Province (20171BAB215046) and the General Program of Natural Science Foundation of Jiangxi Province (20192BAB205069).

\section{Disclosure}

The authors declare no conflicts of interest.

\section{References}

1. Bray F, Ferlay J, Soerjomataram I, et al. Global cancer statistics 2018: GLOBOCAN estimates of incidence and mortality worldwide for 36 cancers in 185 countries. CA Cancer J Clin. 2018;68 (6):394-424.

2. Chen W, Zheng R, Baade PD, et al. Cancer statistics in China, 2015. CA Cancer J Clin. 2016;66(2):115-132.

3. Zimmerman MA, Budish RA, Kashyap S, et al. GPER-novel membrane estrogen receptor. Clin Sci. 2016;130(12):1005-1016. doi:10.1042/CS20160114

4. Revankar CM, Cimino DF, Sklar LA, et al. A transmembrane intracellular estrogen receptor mediates rapid cell signaling. Science. 2005;307(5715):1625-1630. doi:10.1126/science. 1106943

5. Prossnitz ER, Arterburn JB. International union of basic and clinical pharmacology. XCVII. G Protein-Coupled Estrogen Receptor and its pharmacologic modulators. Pharmacol Rev. 2015;67(3):505-540. doi:10.1124/pr.114.009712

6. Filardo EJ, Thomas P. Minireview: G Protein-Coupled Estrogen Receptor-1, GPER-1: its mechanism of action and role in female reproductive cancer, renal and vascular physiology. Endocrinology. 2012;153(7):2953-2962. doi:10.1210/en.20121061

7. Rosenbaum DM, Rasmussen SG, Kobilka BK, et al. The structure and function of G-protein-coupled receptors. Nature. 2009;459 (7245):356-363. doi:10.1038/nature08144

8. Filardo EJ, Quinn JA, Bland KI, et al. Estrogen-induced activation of Erk-1 and Erk-2 requires the G protein-coupled receptor homolog, GPR30, and occurs via trans-activation of the epidermal growth factor receptor through release of HB-EGF. $\mathrm{Mol}$ Endocrinol. 2000;14(10):1649-1660. doi:10.1210/ mend.14.10.0532

9. Bologa CG, Revankar CM, Young SM, et al. Virtual and biomolecular screening converge on a selective agonist for GPR30. Nat Chem Biol. 2006;2(4):207-212. doi:10.1038/nchembio775

10. Dennis MK, Burai R, Ramesh C, et al. In vivo effects of a GPR30 antagonist. Nat Chem Biol. 2009;5(6):421-427. doi:10.1038/ nchembio. 168

11. Prossnitz ER, Hathaway HJ. What have we learned about GPER function in physiology and disease from knockout mice? J Steroid Biochem Mol Biol. 2015;153:114-126. doi:10.1016/j. jsbmb.2015.06.014

12. Yu T, Cheng H, Ding Z, et al. GPER mediates decreased chemosensitivity via regulation of $\mathrm{ABCG} 2$ expression and localization in tamoxifen-resistant breast cancer cells. Mol Cell Endocrinol. 2020;506:110762. doi:10.1016/j.mce.2020.110762 
13. Pupo M, Vivacqua A, Perrotta I, et al. The nuclear localization signal is required for nuclear GPER translocation and function in breast Cancer-Associated Fibroblasts (CAFs).. Mol Cell Endocrinol. 2013;376(1-2):23-32. doi:10.1016/j. mce.2013.05.023

14. Yu T, Yang G, Hou Y, et al. Cytoplasmic GPER translocation in cancer-associated fibroblasts mediates cAMP/PKA/CREB/glycolytic axis to confer tumor cells with multidrug resistance.. Oncogene. 2017;36(15):2131-2145. doi:10.1038/onc.2016.370

15. Prossnitz ER, Barton M. The G-protein-coupled estrogen receptor GPER in health and disease. Nat Rev Endocrinol. 2011;7 (12):715-726. doi:10.1038/nrendo.2011.122

16. Yu T, Liu M, Luo H, et al. GPER mediates enhanced cell viability and motility via non-genomic signaling induced by $17 \beta$-estradiol in triple-negative breast cancer cells. J Steroid Biochem Mol Biol. 2014;143:392-403. doi:10.1016/j.jsbmb.2014.05.003

17. Li Y, Jia Y, Bian Y, et al. Autocrine motility factor promotes endometrial cancer progression by targeting GPER-1. Cell Commun Signal. 2019;17(1):22. doi:10.1186/s12964-019-0336-4

18. Yan Y, Jiang X, Zhao Y, et al. Role of GPER on proliferation, migration and invasion in ligand-independent manner in human ovarian cancer cell line SKOV3. Cell Biochem Funct. 2015;33 (8):552-559. doi:10.1002/cbf.3154

19. Hsu LH, Chu NM, Kao SH. Estrogen, estrogen receptor and lung cancer. Int $J$ Mol Sci. 2017;18(8):1713. doi:10.3390/ ijms 18081713

20. Lau KM, Ma FMT, Xia JT, et al. Activation of GPR30 stimulates GTP-binding of Gail protein to sustain activation of Erk1/2 in inhibition of prostate cancer cell growth and modulates metastatic properties. Exp Cell Res. 2017;350(1):199-209. doi:10.1016/j. yexcr.2016.11.022

21. Chimento A, Sirianni R, Casaburi I, et al. GPER agonist G-1 decreases adrenocortical carcinoma (ACC) cell growth in vitro and in vivo. Oncotarget. 2015;6(22):19190-19203. doi:10.18632/ oncotarget.4241

22. Hsu LH, Chu NM, Lin YF, et al. G-protein coupled estrogen receptor in breast cancer. Int $J$ Mol Sci. 2019;20(2):306. doi:10.3390/ijms20020306

23. Thomas P, Pang Y, Filardo EJ, et al. Identity of an estrogen membrane receptor coupled to a $\mathrm{G}$ protein in human breast cancer cells. Endocrinology. 2005;146(2):624-632. doi:10.1210/ en.2004-1064

24. Liu X, Zhu P, Sham KWY, et al. Identification of a membrane estrogen receptor in zebrafish with homology to mammalian GPER and its high expression in early germ cells of the testis. Biol Reprod. 2009;80(6):1253-1261. doi:10.1095/ biolreprod.108.070250

25. Lappano R, Rosano C, De Marco P, et al. Estriol acts as a GPR30 antagonist in estrogen receptor-negative breast cancer cells. Mol Cell Endocrinol. 2010;320(1-2):162-170. doi:10.1016/j. mce.2010.02.006

26. Thomas P, Dong J. Binding and activation of the seven-transmembrane estrogen receptor GPR30 by environmental estrogens: a potential novel mechanism of endocrine disruption. $J$ Steroid Biochem Mol Biol. 2006;102(1-5):175-179. doi:10.1016/j.jsbmb.2006.09.017

27. Jacenik D, Cygankiewicz AI, Krajewska WM. The G protein-coupled estrogen receptor as a modulator of neoplastic transformation. Mol Cell Endocrinol. 2016;429:10-18. doi:10.1016/j.mce.2016.04.011

28. Sheng ZG, Huang W, Liu YX, et al. Bisphenol A at a low concentration boosts mouse spermatogonial cell proliferation by inducing the $\mathrm{G}$ protein-coupled receptor 30 expression. Toxicol Appl Pharmacol. 2013;267(1):88-94. doi:10.1016/j. taap.2012.12.014
29. Xu S, Yu S, Dong D, et al. G protein-coupled estrogen receptor: a potential therapeutic target in cancer. Front Endocrinol (Lausanne). 2019;10:725. doi:10.3389/fendo.2019.00725

30. Kajta M, Rzemieniec J, Litwa E, et al. The key involvement of estrogen receptor $\beta$ and G-protein-coupled receptor 30 in the neuroprotective action of daidzein. Neuroscience. 2013;238:345-360. doi:10.1016/j.neuroscience.2013.02.005

31. Maggiolini M, Vivacqua A, Fasanella $G$, et al. The $G$ proteincoupled receptor GPR30 mediates c-fos up-regulation by $17 \beta$ estradiol and phytoestrogens in breast cancer cells. J Biol Chem. 2004;279(26):27008-27016. doi:10.1074/jbc.M403588200

32. Dong WH, Chen JC, He YL, et al. Resveratrol inhibits K v 2.2 currents through the estrogen receptor GPR30-mediated PKC pathway. Am J Physiol Cell Physiol. 2013;305(5):C547-C557. doi:10.1152/ajpcell.00146.2013

33. Chimento A, Casaburi I, Rosano C, et al. Oleuropein and hydroxytyrosol activate GPER/GPR 30-dependent pathways leading to apoptosis of ER-negative SKBR 3 breast cancer cells. Mol Nutr Food Res. 2014;58(3):478-489. doi:10.1002/mnfr.201300323

34. Dennis MK, Field AS, Burai R, et al. Identification of a GPER/GPR30 antagonist with improved estrogen receptor counterselectivity. J Steroid Biochem Mol Biol. 2011;127(3-5):358-366. doi:10.1016/j. jsbmb.2011.07.002

35. DeLeon C, Wang HH, Gunn J, et al. A novel GPER antagonist protects against the formation of estrogen-induced cholesterol gallstones in female mice. J Lipid Res. 2020;61(5):767-777. doi:10.1194/jlr.RA119000592

36. Rouhimoghadam M, Lu AS, Salem AK, et al. Therapeutic perspectives on the modulation of G-protein coupled estrogen receptor, GPER, function. Front Endocrinol (Lausanne). 2020;11:877. doi:10.3389/fendo.2020.591217

37. Sharma G, Hu C, Staquicini DI, et al. Preclinical efficacy of the GPER-selective agonist G-1 in mouse models of obesity and diabetes. Sci Transl Med. 2020;12:528. doi:10.1126/scitranslmed.aau5956

38. Sharma G, Prossnitz ER. G-protein-coupled estrogen receptor (GPER) and sex-specific metabolic homeostasis. Sex and gender factors affecting metabolic homeostasis. Diabetes Obes. $2017 ; 427-453$

39. Grande F, Occhiuzzi MA, Lappano R, et al. Computational approaches for the discovery of GPER targeting compounds. Front Endocrinol (Lausanne). 2020;11. doi:10.3389/ fendo.2020.00517

40. Filardo EJ. A role for G-protein coupled estrogen receptor (GPER) in estrogen-induced carcinogenesis: dysregulated glandular homeostasis, survival and metastasis. J Steroid Biochem Mol Biol. 2018;176:38-48. doi:10.1016/j.jsbmb.2017.05.005

41. Brusselaers N, Maret-Ouda J, Konings P, et al. Menopausal hormone therapy and the risk of esophageal and gastric cancer. Int J Cancer. 2017;140(7):1693-1699. doi:10.1002/ijc.30588

42. Chen CL, Kuo MJ, Yen AMF, et al. Gender difference in the association between metabolic factors and hepatocellular carcinoma. JNCI Cancer Spectr. 2020;4(5):pkaa036. doi:10.1093/jncics/pkaa036

43. Rizzo G, Baroni L. Soy, soy foods and their role in vegetarian diets. Nutrients. 2018;10(1):43. doi:10.3390/nu10010043

44. Lu D, Pan C, Ye C, et al. Meta-analysis of soy consumption and gastrointestinal cancer risk. Sci Rep. 2017;7(1):1-14. doi:10.1038/s41598-016-0028-X

45. Zhou Y, Li Y, Zhou T, et al. Dietary natural products for prevention and treatment of liver cancer. Nutrients. 2016;8(3):156. doi:10.3390/nu8030156

46. Azeem S, Gillani SW, Siddiqui A, et al. Diet and colorectal cancer risk in Asia-a systematic review. Asian Pac J Cancer Prev. 2015;16(13):5389-5396. doi:10.7314/APJCP. 2015.16.13.5389 
47. Baralić K, Buha Djordjevic A, Živančević K, et al. Toxic effects of the mixture of phthalates and bisphenol a-subacute oral toxicity study in wistar rats. Int $J$ Environ Res Public Health. 2020;17(3):746. doi:10.3390/ijerph17030746

48. Landrigan P, Stegeman J, Fleming L, et al. Human health and ocean pollution. Ann Glob Health. 2020;86(1):151.

49. Hafezi SA, Abdel-Rahman WM. The endocrine disruptor bisphenol A (BPA) exerts a wide range of effects in carcinogenesis and response to therapy. Curr Mol Pharmacol. 2019;12(3):230. doi:10.2174/1874467212666190306164507

50. Filardo EJ, Thomas P. GPR30: a seven-transmembrane-spanning estrogen receptor that triggers EGF release. Trends Endocrinol Metabol. 2005;16(8):362-367. doi:10.1016/j.tem.2005.08.005

51. Prossnitz ER, Arterburn JB, Smith HO, et al. Estrogen signaling through the transmembrane G protein-coupled receptor GPR30. Аnпи Rev Physiol. 2008;70:165-190. doi:10.1146/annurev. physiol.70.113006.100518

52. Li Y, Chen Y, Zhu ZX, et al. 4-Hydroxytamoxifen-stimulated processing of cyclin $\mathrm{E}$ is mediated via $\mathrm{G}$ protein-coupled receptor 30 (GPR30) and accompanied by enhanced migration in MCF-7 breast cancer cells. Toxicology. 2013;309:61-65. doi:10.1016/j. tox.2013.04.012

53. Sukocheva O, Wadham C, Holmes A, et al. Estrogen transactivates EGFR via the sphingosine 1-phosphate receptor Edg-3: the role of sphingosine kinase-1. J Cell Biol. 2006;173(2):301-310. doi: $10.1083 /$ jcb. 200506033

54. Zucchetti AE, Barosso IR, Boaglio AC, et al. G-protein-coupled receptor 30/adenylyl cyclase/protein kinase A pathway is involved in estradiol 17ß-d-glucuronide-induced cholestasis. Hepatology. 2014;59(3):1016-1029. doi:10.1002/hep.26752

55. Petrie WK, Dennis MK, Hu C, et al. G protein-coupled estrogen receptor-selective ligands modulate endometrial tumor growth. Obstet Gynecol Int. 2013;2013:472720. doi:10.1155/2013/472720

56. Goswami C, Kuhn J, Dina OA, et al. Estrogen destabilizes microtubules through an ion-conductivity-independent TRPV1 pathway. J Neurochem. 2011;117(6):995-1008. doi:10.1111/ j.1471-4159.2011.07270.x

57. Tica AA, Dun EC, Tica OS, et al. G protein-coupled estrogen receptor 1-mediated effects in the rat myometrium. Am J Physiol Cell Physiol. 2011;301(5):C1262-C1269. doi:10.1152/ajpcell.00501.2010

58. Zhou X, Wang S, Wang Z, et al. Estrogen regulates Hippo signaling via GPER in breast cancer. J Clin Invest. 2019;125 (5):2123-2135. doi:10.1172/JCI79573

59. Meyer MR, Clegg DJ, Prossnitz ER, et al. Obesity, insulin resistance and diabetes: sex differences and role of oestrogen receptors. Acta Physiologica. 2011;203(1):259-269. doi:10.1111/ j.1748-1716.2010.02237.x

60. Haas E, Bhattacharya I, Brailoiu E, et al. Regulatory role of G proteincoupled estrogen receptor for vascular function and obesity. Circ Res. 2009;104(3):288-291. doi:10.1161/CIRCRESAHA.108.190892

61. Martensson UEA, Salehi SA, Windahl S, et al. Deletion of the G protein-coupled receptor 30 impairs glucose tolerance, reduces bone growth, increases blood pressure, and eliminates estradiol-stimulated insulin release in female mice. Endocrinology. 2009;150(2):687-698. doi:10.1210/en.2008-0623

62. Sharma G, Hu C, Brigman JL, et al. GPER deficiency in male mice results in insulin resistance, dyslipidemia, and a proinflammatory state. Endocrinology. 2013;154 (11):4136-4145. doi:10.1210/en.2013-1357

63. Esposito K, Chiodini P, Colao A, et al. Metabolic syndrome and risk of cancer: a systematic review and meta-analysis. Diabetes Care. 2012;35(11):2402-2411. doi:10.2337/dc12-0336

64. Girgert R, Emons G, Gründker C. 17ß-estradiol-induced growth of triple-negative breast cancer cells is prevented by the reduction of GPER expression after treatment with gefitinib. Oncol Rep. 2017;37(2):1212-1218. doi:10.3892/or.2016.5306
65. Notas G, Kampa M, Castanas E. G Protein-Coupled Estrogen Receptor in immune cells and its role in immune-related diseases. Front Endocrinol (Lausanne). 2020;11. doi:10.3389/ fendo.2020.579420

66. Jacenik D, Beswick EJ, Krajewska WM, et al. G protein-coupled estrogen receptor in colon function, immune regulation and carcinogenesis. World J Gastroenterol. 2019;25(30):4092-4104. doi:10.3748/wjg.v25.i30.4092

67. Cabas I, Chaves-Pozo E, Mulero V, et al. Role of estrogens in fish immunity with special emphasis on GPER1. Dev Comp Immunol. 2018;89:102-110. doi:10.1016/j.dci.2018.08.001

68. Blasko E, Haskell CA, Leung S, et al. Beneficial role of the GPR30 agonist G-1 in an animal model of multiple sclerosis. $J \quad$ Neuroimmunol. 2009;214(1-2):67-77. doi:10.1016/j. jneuroim.2009.06.023

69. Wei T, Chen W, Wen L, et al. G protein-coupled estrogen receptor deficiency accelerates liver tumorigenesis by enhancing inflammation and fibrosis. Cancer Lett. 2016;382(2):195-202. doi:10.1016/j.canlet.2016.08.012

70. Bodhankar S, Vandenbark AA, Offner H. Oestrogen treatment of experimental autoimmune encephalomyelitis requires $17 \beta-$ oestradiol-receptor-positive B cells that up-regulate PD-1 on CD 4+ Foxp3+ regulatory $\mathrm{T}$ cells. Immunology. 2012;137 (4):282-293. doi:10.1111/imm.12013

71. Natale CA, Li J, Zhang J, et al. Activation of G protein-coupled estrogen receptor signaling inhibits melanoma and improves response to immune checkpoint blockade. Elife. 2018;7:e31770. doi:10.7554/eLife. 31770

72. Natale CA, Li J, Pitarresi JR, et al. Pharmacologic activation of the $\mathrm{G}$ protein-coupled estrogen receptor inhibits pancreatic ductal adenocarcinoma. Cell Mol Gastroenterol Hepatol. 2020;10:868880.e1. doi:10.1016/j.jcmgh.2020.04.016

73. Torre LA, Bray FI, Siegel RL, et al. Global cancer statistics, 2012. CA Cancer J Clin. 2015;65(2):87-108. doi:10.3322/caac.21262

74. Biagioni A, Skalamera I, Peri S, et al. Update on gastric cancer treatments and gene therapies. Cancer Metastasis Rev. 2019;38 (3):537-548. doi:10.1007/s10555-019-09803-7

75. Tan Z. Recent advances in the surgical treatment of advanced gastric cancer: a review. Med Sci Monit. 2019;25:3537-3541. doi:10.12659/MSM.916475

76. Tian S, Zhan N, Li R, et al. Downregulation of G Protein-Coupled Estrogen Receptor (GPER) is associated with reduced prognosis in patients with gastric cancer. Med Sci Monit. 2019;25:3115-3126. doi:10.12659/MSM.913634

77. Lee SJ, Kim TW, Park GL, et al. G protein-coupled estrogen receptor-1 agonist induces chemotherapeutic effect via ER stress signaling in gastric cancer. BMB Rep. 2019;52(11):647-652. doi:10.5483/BMBRep.2019.52.11.007

78. Zheng S, Yang L, Dai Y, et al. Screening and survival analysis of hub genes in gastric cancer based on bioinformatics. J Comp Biol. 2019;26(11):1316-1325. doi:10.1089/cmb.2019.0119

79. Akinyemiju T, Abera S, Ahmed M, et al. The burden of primary liver cancer and underlying etiologies from 1990 to 2015 at the global, regional, and national level: results from the Global Burden of Disease Study 2015. JAMA Oncol. 2017;3(12):1683-1691. doi:10.1001/jamaoncol.2017.3055

80. El-Serag HB, Rudolph KL. Hepatocellular carcinoma: epidemiology and molecular carcinogenesis. Gastroenterology. 2007;132 (7):2557-2576. doi:10.1053/j.gastro.2007.04.061

81. Zhang Y, Ren JS, Shi JF, et al. International trends in primary liver cancer incidence from 1973 to 2007. BMC Cancer. 2015;15 (1):94. doi:10.1186/s12885-015-1113-4

82. Kur P, Kolasa-Wołosiuk A, Misiakiewicz-Has K, et al. Sex hormone-dependent physiology and diseases of liver. Int J Environ Res Public Health. 2020;17(8):2620. doi:10.3390/ ijerph17082620 
83. Sukocheva OA. Estrogen, estrogen receptors, and hepatocellular carcinoma: are we there yet? World J Gastroenterol. 2018;24 (1):1-4. doi:10.3748/wjg.v24.i1.1

84. Przybyszewska J, Żekanowska E. The role of hepcidin, ferroportin, HCP1, and DMT1 protein in iron absorption in the human digestive tract. Przeglad Gastroenterol. 2014;9(4):208. doi:10.5114/pg.2014.45102

85. Ikeda Y, Tajima S, Izawa-Ishizawa Y, et al. Estrogen regulates hepcidin expression via GPR30-BMP6-dependent signaling in hepatocytes. PLoS One. 2012;7(7):e40465. doi:10.1371/journal. pone.0040465

86. Ulitzky L, Lafer MM, KuKuruga MA, et al. A new signaling pathway for HCV inhibition by estrogen: GPR30 activation leads to cleavage of occludin by MMP-9. PLoS One. 2016;11(1): e0145212. doi:10.1371/journal.pone.0145212

87. Cortes E, Lachowski D, Rice A, et al. Tamoxifen mechanically deactivates hepatic stellate cells via the G protein-coupled estrogen receptor. Oncogene. 2019;38(16):2910-2922. doi:10.1038/ s41388-018-0631-3

88. Shen M, Shi H, Migliaccio A. Estradiol and estrogen receptor agonists oppose oncogenic actions of leptin in HepG2 cells. PLoS One. 2016;11(3):e0151455. doi:10.1371/journal.pone.0151455

89. Chaturantabut S, Shwartz A, Evason KJ, et al. Estrogen activation of G-protein-coupled estrogen receptor 1 regulates phosphoinositide 3-kinase and mTOR signaling to promote liver growth in zebrafish and proliferation of human hepatocytes. Gastroenterology. 2019;156(6):1788-1804. e13. doi:10.1053/j. gastro.2019.01.010

90. Teng Y, Radde BN, Litchfield LM, et al. Dehydroepiandrosterone activation of G-protein-coupled estrogen receptor rapidly stimulates microRNA-21 transcription in human hepatocellular carcinoma cells. J Biol Chem. 2015;290(25):15799-15811. doi:10.1074/jbc.M115.641167

91. Kuhajda FP. Fatty acid synthase and cancer: new application of an old pathway. Cancer Res. 2006;66(12):5977-5980. doi:10.1158/ 0008-5472.CAN-05-4673

92. Santolla MF, Lappano R, De Marco P, et al. G protein-coupled estrogen receptor mediates the up-regulation of fatty acid synthase induced by $17 \beta$-estradiol in cancer cells and cancerassociated fibroblasts. J Biol Chem. 2012;287(52):43234-43245. doi:10.1074/jbc.M112.417303

93. Baldissera VD, Alves AF, Almeida S, et al. Hepatocellular carcinoma and estrogen receptors: polymorphisms and isoforms relations and implications. Med Hypotheses. 2016;86:67-70. doi:10.1016/j.mehy.2015.11.030

94. Rahib L, Smith BD, Aizenberg R, et al. Projecting cancer incidence and deaths to 2030: the unexpected burden of thyroid, liver, and pancreas cancers in the United States. Cancer Res. 2014;74 (11):2913-2921. doi:10.1158/0008-5472.CAN-14-0155

95. Andersson G, Borgquist S, Jirstrom K. Hormonal factors and pancreatic cancer risk in women: the Malmö Diet and Cancer Study. Int J Cancer. 2018;143(1):52-62. doi:10.1002/ijc.31302
96. Mesmar F, Dai B, Ibrahim AF, et al. Clinical candidate and genistein analogue AXP107-11 has chemoenhancing functions in pancreatic adenocarcinoma through $\mathrm{G}$ protein-coupled estrogen receptor signaling. Cancer Med. 2019;8(18):7705-7719. doi:10.1002/cam4.2581

97. Rice A, Cortes E, Lachowski D, et al. GPER activation inhibits cancer cell mechanotransduction and basement membrane invasion via RhoA. Cancers. 2020;12(2):289. doi:10.3390/ cancers 12020289

98. Erkan M, Hausmann S, Michalski CW, et al. The role of stroma in pancreatic cancer: diagnostic and therapeutic implications. Nat Rev Gastroenterol Hepatol. 2012;9(8):454-467. doi:10.1038/ nrgastro.2012.115

99. Cortes E, Lachowski D, Robinson B, et al. Tamoxifen mechanically reprograms the tumor microenvironment via HIF-1A and reduces cancer cell survival. EMBO Rep. 2019;20(1):e46557. doi:10.15252/embr.201846557

100. Cortes E, Sarper M, Robinson B, et al. GPER is a mechanoregulator of pancreatic stellate cells and the tumor microenvironment. EMBO Rep. 2019;20(1):e46556. doi:10.15252/embr.201846556

101. Barzi A, Lenz AM, Labonte MJ, et al. Molecular pathways: estrogen pathway in colorectal cancer. Clin Cancer Res. 2013;19(21):5842-5848. doi:10.1158/1078-0432.CCR-13-0325

102. Liu Q, Chen Z, Jiang G, et al. Epigenetic down regulation of G protein-coupled estrogen receptor (GPER) functions as a tumor suppressor in colorectal cancer. Mol Cancer. 2017;16(1):87. doi:10.1186/s12943-017-0654-3

103. Konstantinopoulos PA, Kominea A, Vandoros G, et al. Oestrogen receptor beta $(\mathrm{ER} \beta)$ is abundantly expressed in normal colonic mucosa, but declines in colon adenocarcinoma paralleling the tumour's dedifferentiation. Eur $J$ Cancer. 2003;39 (9):1251-1258. doi:10.1016/S0959-8049(03)00239-9

104. Rudolph A, Toth C, Hoffmeister M, et al. Expression of oestrogen receptor $\beta$ and prognosis of colorectal cancer. $\mathrm{Br} J$ Cancer. 2012;107(5):831-839. doi:10.1038/bjc.2012.323

105. Bustos V, Nolan ÁM, Nijhuis A, et al. GPER mediates differential effects of estrogen on colon cancer cell proliferation and migration under normoxic and hypoxic conditions. Oncotarget. 2017;8 (48):84258-84275. doi:10.18632/oncotarget.20653

106. Gilligan LC, Gondal A, Tang V, et al. Estrone sulfate transport and steroid sulfatase activity in colorectal cancer: implications for hormone replacement therapy. Front Pharmacol. 2017;8:103. doi:10.3389/fphar.2017.00103

107. Gilligan LC, Rahman HP, Hewitt AM, et al. Estrogen activation by steroid sulfatase increases colorectal cancer proliferation via GPER. J Clin Endocrinol Metab. 2017;102(12):4435-4447. doi:10.1210/jc.2016-3716
OncoTargets and Therapy

\section{Publish your work in this journal}

OncoTargets and Therapy is an international, peer-reviewed, open access journal focusing on the pathological basis of all cancers, potential targets for therapy and treatment protocols employed to improve the management of cancer patients. The journal also focuses on the impact of management programs and new therapeutic agents and protocols on patient perspectives such as quality of life, adherence and satisfaction. The manuscript management system is completely online and includes a very quick and fair peer-review system, which is all easy to use. Visit http://www.dovepress.com/ testimonials.php to read real quotes from published authors. 